\title{
The restriction produced by the air filtration system versus the restriction produced by the air filter
}

\author{
Marius Toma*, Cornelia Stan and Iordan Fileru \\ Automotive Engineering Dept., Faculty of Transports, University Politehnica of Bucharest, Romania
}

\begin{abstract}
The air filtration system for an internal combustion engine comprises the air filter, the filter housing and the intake air duct which conducts the air flow from the vehicle grille to the filter housing. This generates gaso-dynamic resistances to the air intake into the engine. The air filter housing and the intake air duct are often mounted in the engine compartment mainly where it fits better and less according to the air flow and noise reduction criteria. The paper aims to show the contribution of the restriction produced by the filter housing and the intake air duct to the total restriction produced by the air filtration system. Several air filtration systems from vehicles fitted with both spark-ignition engines and diesel engines are tested. The results show that the restriction produced by the intake air duct system as well as the air filter housing have a significant contribution to the total restriction produced by the air filtration system of a vehicle engine.
\end{abstract}

\section{Introduction}

The air contains a multitude of impurities of different sizes and different chemical nature thus representing the main source of harmful impurities for the engine. To prevent dust particles from reaching the engine kinematic pairs, the air is filtered through the air filtration system [1]. The air supply systems are designed to meet multiple engine requirements: durability, protection against impurities, organizing the airflow to get the lowest resistance, low noise, high energy performance, ease of maintenance, protection against water or snow admission, the best fit in the engine compartment, etc. [2-4]. As shown in [2], the location of the air filters in the engine compartment represent a compromise between the requirements listed above. Usually, the filter system is located in the engine compartment where there is enough space to allow easy maintenance and not where it would be best for the air flow. This results in a large variety of shapes of the air filtration systems: circular, prismatic or irregular shaped cases, intake air ducts of different lengths, perforated or not, flexible or not. The resistances of the air intake system are quantified through restriction - static pressure measured immediately downstream of the unit under test, according to ISO 5011 [5].

\footnotetext{
${ }^{*}$ Corresponding author: marius.toma@upb.ro
} 


\section{Literature references concerning the air filters restriction}

The air filters, together with the intake system, introduce pressure resistances which, at high values, cause a decrease in engine power. The acceptable relative reduction in engine power due to the air intake system is usually $2-3 \%$, according to [6,7]. Clogging the air filter has no significant effect on the fuel economy of the motor vehicles equipped with gasoline engine control systems [8] as well as in modern diesel engines [9].

In the paper [3] it is shown that for the light / medium duty engine air cleaners, the nominal restriction, strictly on the filter side, must be $0.125 \div 0.75 \mathrm{kPa}$, and from the entire air filtration system, $2 \div 4 \mathrm{kPa}$.

\section{Preparing and conducting the experimental research}

The aim of the research is to measure the restriction produced in the air filtration system for three different configurations: the complete air intake system (AIS) as fitted to the motor vehicle, only the housing and the air filter (H\&AF), and the air intake system without the air filter (AIS - AF). The results are used to determine the restriction produced strictly by the air filters (AF) and by intake air ducts (IAD), to compare them with the restriction produced by the entire air intake system (AIS).

The tests were carried out on a specialized air filter test stand (Figure 1) at the Politehnica University of Bucharest, Faculty of Transports, Automotive Engineering Department.

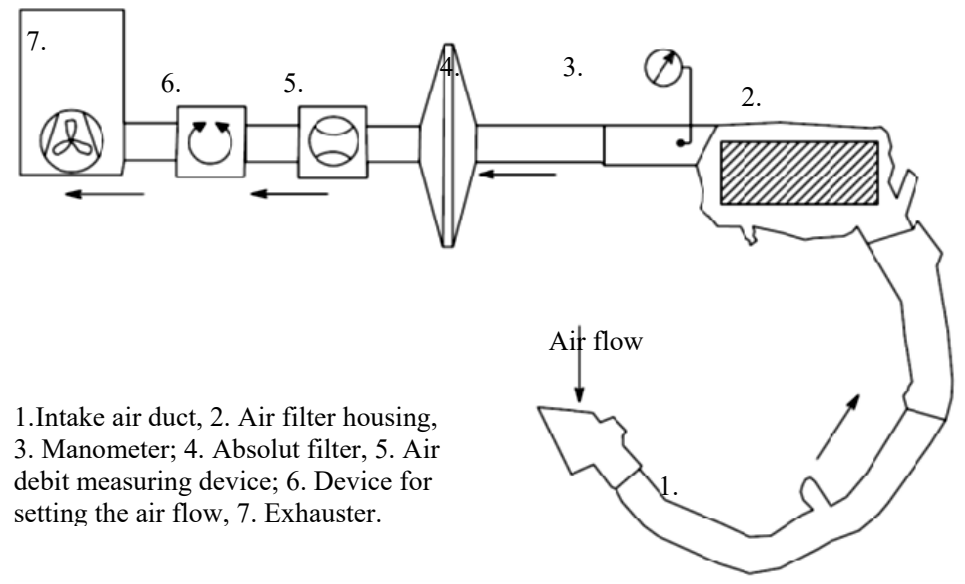

Fig. 1. The scheme of the stand.

Experimental research was performed on six air filtration systems (Figure 2) from both spark ignition engines and diesel engines, using OEM (original equipment manufacturer) air filters only. Each housing is adapted to measure the restriction, as shown in "Detail of the restriction measurement nozzle" (Figure 2).

The test modes for the air filtration system, in order to measure the restriction are:

- at the maximum air flow rate of the engine on which it was mounted (Qmax);

- at $50 \%$ of the maximum flow rate $(50 \%$ of Qmax);

- at $25 \%$ of the maximum flow rate ( $25 \%$ of Qmax).

Testing the filters at the maximum flow rate is recommended in [5]. The lower flow test is recommended in [1] because the vehicle is rarely used at full load during use.

Table 1 lists the constructive and functional characteristics of the engines and the air filters that fit them. 


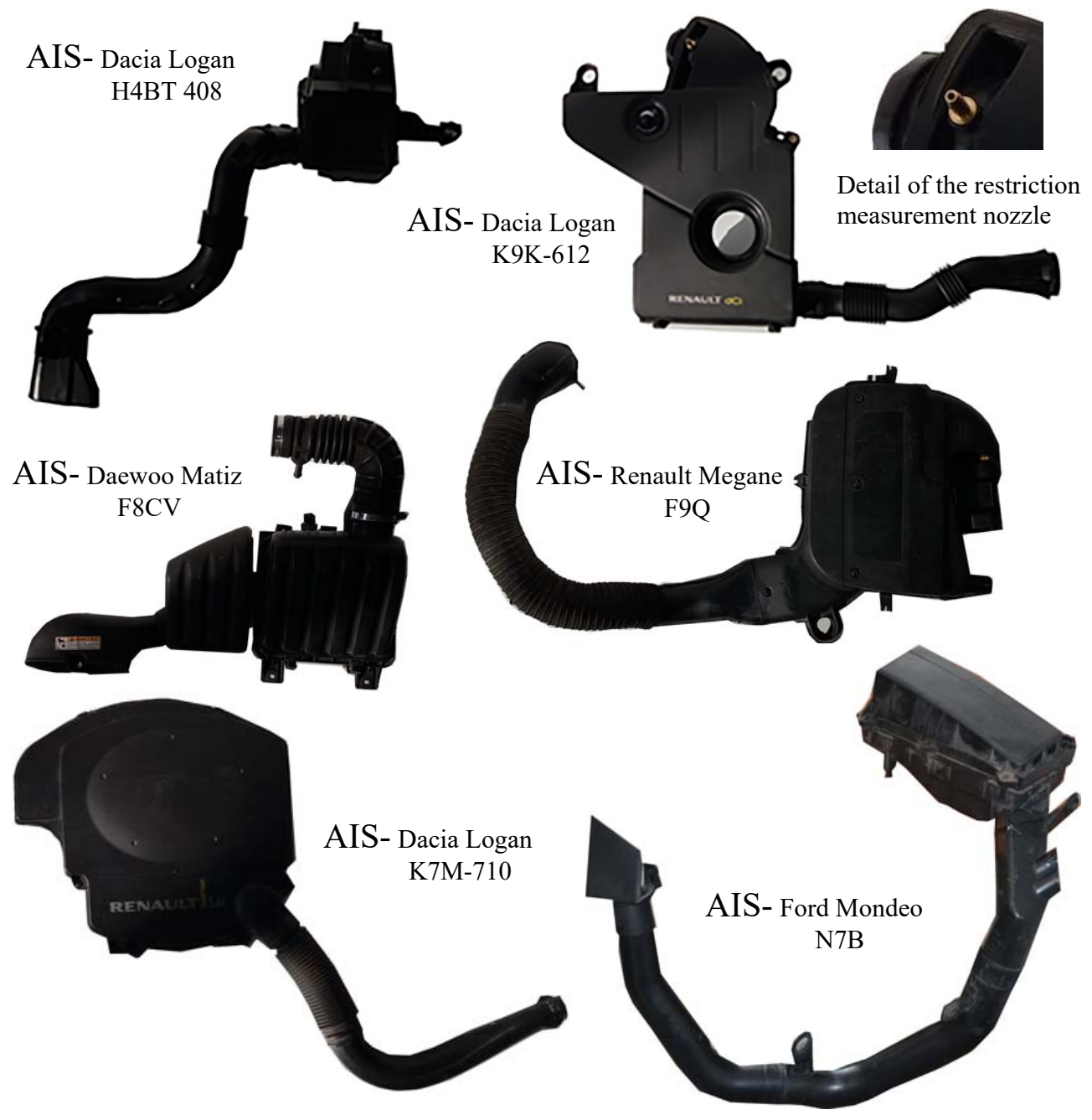

Fig. 2. Air filtration systems tested.

Table 1. The constructive and functional characteristics of the engines and air filters that fit them.

\begin{tabular}{|c|c|c|c|c|c|c|c|}
\hline $\begin{array}{c}\text { Vehicle and } \\
\text { engine type }\end{array}$ & $\begin{array}{c}\text { Displace- } \\
\text { ment }\end{array}$ & $\begin{array}{c}\text { Maximum } \\
\text { engine } \\
\text { power }\end{array}$ & $\begin{array}{c}\text { Maximum } \\
\text { engine air } \\
\text { flow rate }\end{array}$ & $\begin{array}{c}\text { Air filter } \\
\text { area }\end{array}$ & $\begin{array}{c}\text { Filter } \\
\text { material }\end{array}$ & $\begin{array}{c}\text { IAD } \\
\text { length }\end{array}$ & $\begin{array}{c}\text { IAD } \\
\text { Area }\end{array}$ \\
\hline $\begin{array}{c}\text { Dacia Logan } \\
\text { H4BT 408 }\end{array}$ & 900 & 66 & $252[10]$ & 0.403 & $\begin{array}{c}\text { nonwoven } \\
\text { fabric /felt }\end{array}$ & 0.62 & 0.00295 \\
\hline $\begin{array}{c}\text { Dacia Logan } \\
\text { K7M 710 }\end{array}$ & 1600 & 64 & $237[1]$ & 0.802 & paper & 0.55 & 0.00189 \\
\hline $\begin{array}{c}\text { Daewoo } \\
\text { Matiz - F8CV }\end{array}$ & 796 & 37 & $154[11]$ & 0.1496 & $\begin{array}{c}\text { nonwoven } \\
\text { fabric/felt }\end{array}$ & 0.26 & 0.00323 \\
\hline $\begin{array}{c}\text { Dacia Logan } \\
\text { K9K 612 }\end{array}$ & 1461 & 65 & $321[10]$ & 0.286 & $\begin{array}{c}\text { nonwoven } \\
\text { fabric /felt }\end{array}$ & 0.46 & 0.00191 \\
\hline $\begin{array}{c}\text { Renault } \\
\text { Megane - F9Q }\end{array}$ & 1870 & 59 & $343[11]$ & 0.605 & paper & 0.80 & 0.00658 \\
\hline $\begin{array}{c}\text { Ford Mondeo } \\
\text { N7B }\end{array}$ & 1998 & 96 & $349[11]$ & 0.857 & paper & 1.12 & 0.00181 \\
\hline
\end{tabular}


The area of the filtering surface of each filter was calculated according to the number of folds of the filter material and their size. To determine the IAD area, the outline footprint was drawn and then the surface was calculated using a computer.

\section{Results and their interpretation}

Following the experiments performed, the restrictions for each air filtering system were determined for all three test modes, and were graphically represented in Figures 3 to 8.

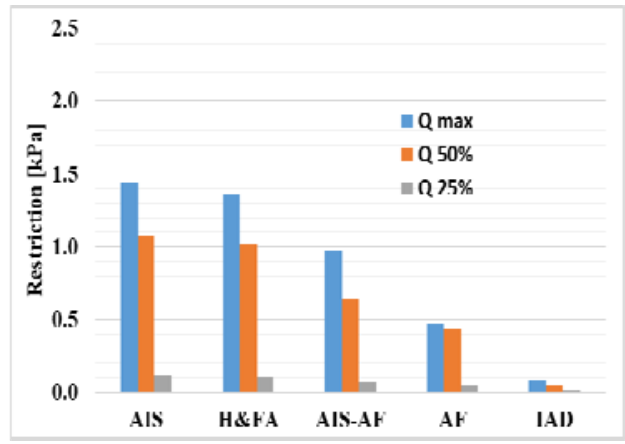

Fig. 3. Restrictions of Dacia Logan / H4BT 408.

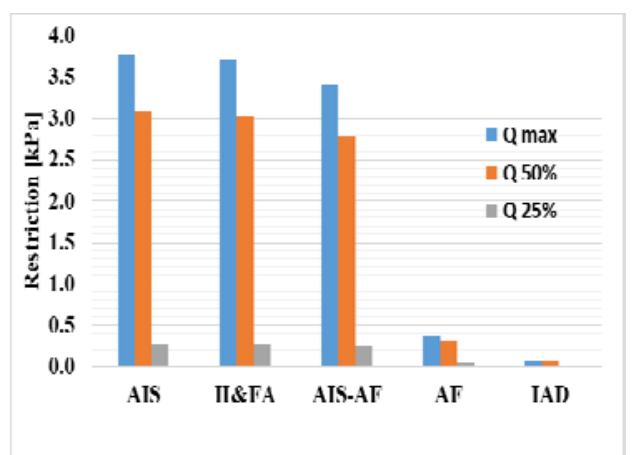

Fig. 5. Restriction of Daewoo Matiz / F8CV.

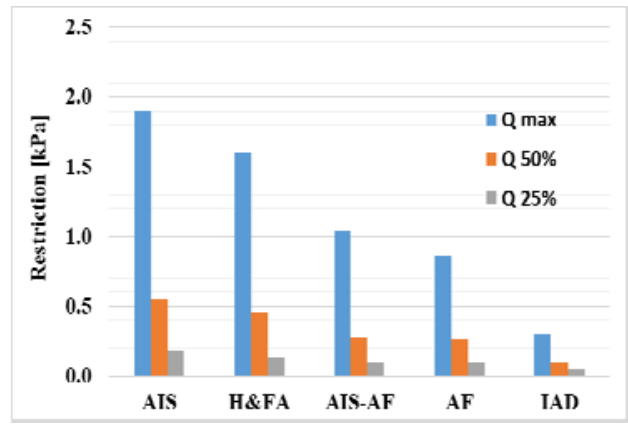

Fig. 7. Restrictions of Renault Megane / F9Q.

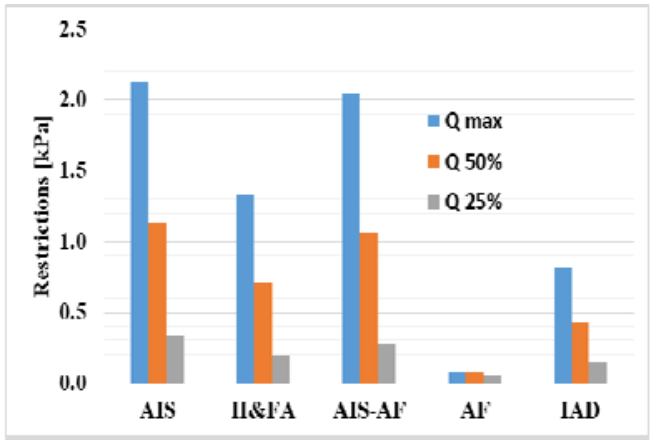

Fig. 4. Restrictions of Dacia Logan / K7M-710.

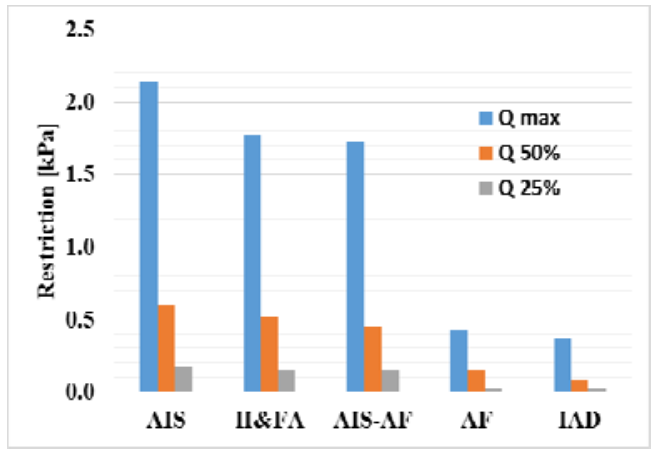

Fig. 6. Restrictions of Dacia Logan / K9K-612.

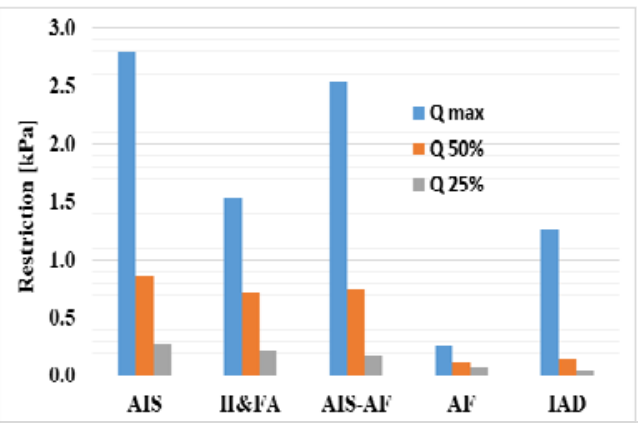

Fig. 8. Restrictions of Ford Mondeo / N7B. 
At the test mode corresponding to the maximum flow, the restriction produced by AIS varies between $1.45 \mathrm{kPa}$ and $3.8 \mathrm{kPa}$. These values are close to the range of $2 \div 4 \mathrm{kPa}$ recommended in paper [3] for AIS designed for light / medium duty Engine Air Cleaners.

The lowest value is recorded for the AIS of the Dacia Logan car with the H4BT 408 engine, (Figure 3). The same AIS equips the K9K 658 engine which has a maximum air con-sumption of $334 \mathrm{~kg} / \mathrm{h}$ [10], so for the H4BT 408 engine with a maximum air consumption of $252 \mathrm{~kg} / \mathrm{h}$, the AIS is slightly oversized and has a low resistence. The IAD of this system has also the smallest measured restrictions, being the only one with slits applied over the entire length of the tube, thus having a reduced contribution to the total AIS restriction.

The biggest restriction was produced by the Daewoo Matiz- F8CV engine AIS (Figure 5). The system is very compact and the air inside the housing passes through a narrow tube that leads to a significant increase in restriction.

Also, for the two engine models mentioned above, the AIS-AF restrictions have the lowest and the highest values. The range of AIS-AF restriction for all six models is $0.98 \div$ $3.4 \mathrm{kPa}$. These values show that most of the AIS restriction is attributed to the air ducts and housing and less to the air filter.

In order to highlight these aspects, the air filter restriction (as a difference between AIS and AIS-AF) and the IAD restriction (difference between AIS and H \& FA) were calculated and plotted alongside the other constraints measured. Table 2 shows the share of $\mathrm{AF}$ and IAD restriction in total system restriction.

Table 2. The share of AF and IAD restriction in total system restriction.

\begin{tabular}{|l|c|c|c|c|}
\hline \multicolumn{1}{|c|}{$\begin{array}{c}\text { Vehicle and } \\
\text { engine type }\end{array}$} & $\begin{array}{c}\text { Air Filter } \\
\text { Restriction }\end{array}$ & $\begin{array}{c}\text { Air Filter } \\
\text { Share }\end{array}$ & $\begin{array}{c}\text { IAD } \\
\text { Restriction }\end{array}$ & $\begin{array}{c}\text { IAD } \\
\text { Share }\end{array}$ \\
\hline Dacia Logan / H4BT 408 & $\mathrm{kPa}$ & $\%$ & $\mathrm{kPa}$ & $\%$ \\
\hline Dacia Logan / K7M-710 & 0.468 & 32.4 & 0.080 & 5.5 \\
\hline Daewoo Matiz / F8CV & 0.100 & 3.9 & 0.800 & 38.1 \\
\hline Dacia Logan / K9K-612 & 0.372 & 9.8 & 0.059 & 1.6 \\
\hline Renault Megane / F9Q & 0.417 & 19.5 & 0.364 & 17 \\
\hline Ford Mondeo / N7B & 0.257 & 9.2 & 1.266 & 45.2 \\
\hline
\end{tabular}

Restrictions produced by the air filters tested are close to the range of $0.125 \div 0.750 \mathrm{kPa}$ specified in the paper [3], and the papers [12] and [13] specify restrictions for air filters of the same order of magnitude. These values depend on the constructive and functional particularities of the filters (type of filter material, area of the filtering surface).

Although the Ford Mondeo / N7B air filter has the largest surface area, it is also crossed by the highest airflow between the tested systems (Table 1). At the increasing of the flow through a filter the resistance increases significantly [1]. A large filtration area crossed by a small flow leads to low constraints as seen in AIS for Dacia Logan / K7M-710. Measuring the restriction produced by $\mathrm{H} \& \mathrm{AF}$ reflects the contribution that $\mathrm{IAD}$ has to total restriction. At the maximum flow rate, the lowest restriction of $0.059 \mathrm{kPa}$ is noted at the Daewoo Matiz / F8CV because the IAD is very short and has a large suction mouth (Table 1). The biggest restriction produced by IAD was measured at the Renault Megan-F9Q. Although it has a large suction mouth compared to other systems, the IAD is the longest and is made of a very dense and hardened textile material and not with smooth plastic walls, as with other systems. Regarding the variation of the restriction with the intake air flow, it can be noticed that the restriction produced by AIS decreases with the decrease of the air flow. Observation is valid for all tested systems. The decrease is not uniform and depends on the constructive features of AIS. It can be seen that for five out of the six tested systems, the restriction measured at 25\% of Qmax does not exceed 10\% of the value 
corresponding to Qmax. Therefore, in order that the air filter testing to be relevant, this must be done at the maximum flow rate of the engine that it equips, as recommended in [5].

\section{Conclusions}

The most of the total air intake system (AIS) restriction is produced by the intake air ducts (IAD) and the filter housing (H), and less by the air filter (AF) itself. Taking into account the significant contribution of the air ducts and housing to the total AIS restriction, it is advisable to replace the current systems with a maintenance-free AIS. This will use "lifetime" or "zero maintenance" air filters and the IAD \& H will have a construction that will reduce the restriction as much as possible to improve the cylinders charging. In paper [2], it is recommended to use a multi-layer wet film filter for a zero-maintenance AIS.

The IAD can be removed easily without any change being noticed in engine's operation. This reduces the restriction caused by the air supply system, but the intake air will be warmer and will adversely affect the cylinder filling with fresh charge.

This work has been funded by University Politehnica of Bucharest, through the "Excellence Research Grants” Program, UPB - GEX 2017. Identifier: UPB- GEX2017, Ctr. No. TR 27-17-06 /2017”.

\section{References}

1. M. Toma, Researches on the Influence of Maintenance Activity of Air Filters on the Dynamic Performances of Automotive Internal Combustion Engines (Ph.D. thesis, Bucuresti 2013, p.18)

2. N.J. Bugli, G. S. Green, Performance and Benefits of Zero Maintenance Air Induction, SAE technical paper series 2005-01-1139

3. N.J. Bugli, Service Life Expectations and Filtration Performance of Engine Air Cleaners, SAE technical paper series 2000-01-3317

4. M. Gailis, V.Pirs, Proc. $10^{\text {th }}$ Engineering for rural development Conference, 173-178, Latvia University of Agriculture, Jelgava (2011)

5. *** ISO 5011, "Inlet air cleaning equipment for internal combustion engines and compressors - Performance testing", 2nd edition 2000-12-01, Corrected and reprinted 2001-07-15

6. T. Jaroszczyk, C. Pardue, E. Holm, Journal of KONES Internal Combustion Engines 11, 1-2, 259-275 (2004)

7. M. Lisowski, TEKA Kom. Mot. Energ. Roln. - OL PAN, 155-163 (2009)

8. J. Thomas, B. West and S. Huffand, K. Norman, Effect of intake air filter condition on light-duty gasoline vehicles, SAE technical paper, 2012-01-1717

9. J. Thomas, B. West and S. Huffand, Effect of Air Filter Condition on Diesel VehicleFuelEconomy, SAE technical paper series, 2013-01-031

10. *** Mechanical Test Dept., Technical engine test reports (Titu Technical Center, 2011)

11. N. Negurescu, C. Pana, M. G. Popa, Spark ignition engines. Processes, (Matrixrom, Bucuresti, 2nd Edition, 2013)

12. A. H., Badawy Megahed, "Introducing a new parameter that effects the performance of engine pleated air filter", SAE technical paper series. 2011-01-2466

13. U. Stahl, H. Reinhardt, New Nonwoven Media for Engine Intake Air Filtration with Improved Performances, SAE technical paper series 2006-01-0272 